\title{
Ramping Up Antimicrobial Peptides Against Severe Acute Respiratory Syndrome Coronavirus-2
}

\author{
Santosh K. Ghosh and Aaron Weinberg* \\ Department of Biological Sciences, Case Western Reserve University, Cleveland, $\mathrm{OH}$, United States
}

\section{OPEN ACCESS}

Edited by: Annalisa Pastore,

King's College London, United Kingdom

Reviewed by:

Gill Diamond,

University of Louisville, United States Anirban Bhunia,

Bose Institute, India Peter G. Barlow, Edinburgh Napier University, United Kingdom

*Correspondence: Aaron Weinberg axw47@case.edu

Specialty section: This article was submitted to Molecular Diagnostics and Therapeutics, a section of the journal Frontiers in Molecular Biosciences

Received: 23 October 2020 Accepted: 27 May 2021

Published: 21 June 2021

Citation: Ghosh SK and Weinberg A (2021) Ramping Up Antimicrobial Peptides Against Severe Acute Respiratory

Syndrome Coronavirus-2.

Front. Mol. Biosci. 8:620806. doi: 10.3389/fmolb.2021.620806
Human-derived antimicrobial peptides (AMPs), such as defensins and cathelicidin LL-37, are members of the innate immune system and play a crucial role in early pulmonary defense against viruses. These AMPs achieve viral inhibition through a variety of mechanisms including, but not limited to, direct binding to virions, binding to and modulating host cell-surface receptors, blocking viral replication, and aggregation of viral particles and indirectly by functioning as chemokines to enhance or curb adaptive immune responses. Given the fact that we are in a pandemic of unprecedented severity and the urgent need for therapeutic options to combat severe acute respiratory syndrome coronavirus-2 (SARS-CoV-2), naturally expressed AMPs and their derivatives have the potential to combat coronavirus disease 2019 (COVID-19) and impede viral infectivity in various ways. Provided the fact that development of effective treatments is an urgent public health priority, AMPs and their derivatives are being explored as potential prophylactic and therapeutic candidates. Additionally, cell-based platforms such as human mesenchymal stem cell (hMSC) therapy are showing success in saving the lives of severely ill patients infected with SARS-CoV-2. This could be partially due to AMPs released from hMSCs that also act as immunological rheostats to modulate the host inflammatory response. This review highlights the utilization of AMPs in strategies that could be implemented as novel therapeutics, either alone or in combination with other platforms, to treat CoV-2-infected individuals.

Keywords: antimicrobial peptides (AMPs), coronavirus, COVID-19, defensins, LL-37, MSCs, vitamin D3

\section{INTRODUCTION}

The ongoing coronavirus disease 2019 (COVID-19) pandemic, the result of infection by SARS-CoV2 , continues to spread worldwide and has already claimed the lives of over three million people (John Hopkins University, 2020). This untenable situation requires the discovery of novel therapeutic approaches, alone and/or in conjunction with existing approved regimens, to impede the virus's relentless spread. Naturally occurring cationic peptides with broad-spectrum microbicidal activity, referred to as antimicrobial peptides (AMPs), are a key component of our body's innate immune defense against bacteria, fungi, and viruses (Brice and Diamond, 2020). Much of their antimicrobial activity is dependent upon electrostatic interactions between anionic components of microbial membranes and AMP cationic charges. Since the AMPs possess a wide range of activities in modulating the functions of various host cells as part of innate immunity, they have also been referred to in the literature as host defense peptides (HDPs) and cationic host defense peptides (CHDPs) (Hancock et al., 2016; Mookherjee et al., 2020). AMPs are known to kill microbes through 
direct activity involving a variety of mechanisms, including membrane permeation, disruption of electrochemical gradients, and inhibition of metabolic processes (Brogden, 2005; Prasad et al., 2019). Furthermore, these peptides interact with multiple receptors on host cells, such as toll-like receptors (TLRs) and chemokine receptors, as well as inflammasomes and members of the host's complement system, thereby providing a bridge between innate and adaptive immunity (Hancock et al., 2016; Prasad et al., 2019; Mookherjee et al., 2020). Although more classes of AMPs occur in humans, the $\alpha$ - and $\beta$-defensins and cathelicidin LL-37 have been studied the most (Doss et al., 2010; Ahmed et al., 2019a; Brice and Diamond, 2020). Herein, we review how these AMPs act as antiviral agents and discuss how they may also be exploited to address SARS-CoV-2.

\section{An Overview of Antimicrobial Peptides: Defensins and LL-37}

Defensins are a family of small $(3-5 \mathrm{kDa}), \beta$-sheeted, cysteine-rich, cationic, and amphipathic peptides, which belong to either the $\alpha, \beta$, or $\theta$ subfamily. $\alpha$-Defensins are found in lysosomal compartments of neutrophils and macrophages, as well as in Paneth cells within the crypts of the small intestines. There are four human neutrophil a-defensins referred to as human neutrophil peptides (HNPs) 1, 2, 3, and 4. All four play an important role in killing phagocytosed microbes by professional phagocytes (Soehnlein et al., 2008; Nordenfelt and Tapper, 2011). Enteric $\alpha$-defensins are referred to as human defensins (HDs) 5 and 6, where HD5 plays an important role in maintaining microbial homeostasis of the gut microbiota, while HD6 forms nets to entrap gastrointestinal pathogens within the lumen and prevent them from invading gut tissue (Chairatana and Nolan, 2017). Human $\beta$-defensins (hBDs)-1, $-2,-3$, and -4 are expressed in epithelial cells of various mucosal sites and participate in the mucosal innate immune defense against microbial colonization and invasion (Suarez-Carmona et al., 2015). Theta $(\theta)$-defensins are produced by old world monkeys and orangutans but not humans. Human $\theta$-defensin genes contain a premature stop codon that prevents effective translation (Lehrer et al., 2012). Synthetic $\theta$-defensins with sequences that correspond to those that are encoded within the human pseudogenes are called retrocyclins (Lehrer et al., 2012). The antiviral activity of defensins was originally attributed to their lipid perturbation activity, as disruption of viral-host protein receptor interaction by lipid perturbation of the viral membrane leads to the inhibition of receptor binding so that fusion of the enveloped virus to host cells is prevented (Wilson et al., 2013). However, the observation that several classes of non-enveloped viruses are also sensitive to defensins led to the discovery of additional defensin-related antiviral mechanisms (Wilson et al., 2013; Park et al., 2018; Brice and Diamond, 2020). These include extracellular viral aggregation, blocking uncoating of the virus, and preventing nuclear import (Wilson et al., 2013). Additional AMP activities against enveloped viruses include blocking virus binding to host receptors, receptor downregulation, inhibition of viral fusion with the host membrane, blocking reverse transcription, modulating cell signaling, and blocking gene expression (Quiñones-Mateu et al., 2003; Furci et al., 2007; Kota et al., 2008; Wilson et al., 2013; Park et al., 2018).
The only member of the cathelin family of AMPs in humans is referred to as the human cationic antimicrobial peptide (hCAP) (Zanetti et al., 1995). The "cathelin" name refers to the conserved domain in the pro-peptide that is part of the inactive precursor, and the entire protein has a molecular weight of $18 \mathrm{kDa}$; hence, it is also referred to as hCAP18. The active C-terminal-associated 37 amino acid of hCAP18, starting with double leucines, is referred to as LL-37 (Xhindoli et al., 2016). LL-37 possesses direct microbicidal activity against bacteria, fungi, and multiple enveloped and non-enveloped viruses (Doss et al., 2010; Barlow et al., 2011; Xhindoli et al., 2016; Brice and Diamond, 2020; Chessa et al., 2020) including several respiratory viruses (Currie et al., 2013; Currie et al., 2016; Harcourt et al., 2016; Sousa et al., 2017). LL-37 also acts to modulate immune responses and functions in concert with TLRs to communicate an imminent threat to the immune system (Barlow et al., 2011; Ahmed et al., 2019b).

\section{Antimicrobial Peptides Against Respiratory Viruses: Modes of Action}

Bacteria and viruses are recurring causative agents of pulmonary diseases in humans, with respiratory viruses playing a disproportionately higher etiological role (Denny, 1995; Leung, 2021). They contribute to a significant impact on morbidity, mortality, and economics worldwide, as documented and chronicled by the World Health Organization (GBD 2017 Influenza Collaborators, 2019). The most common respiratory viruses are influenza A virus (IAV), respiratory syncytial virus (RSV), parainfluenza virus (PIV), metapneumovirus (MPV), human rhinovirus (HRV), human adenovirus (HAdV), bocavirus (BoV), and coronavirus ( $\mathrm{CoV}$ ) (Boncristiani et al., 2009; Weston et al., 2019).

Defensins and LL-37 have demonstrated antiviral activities against a variety of these viruses (summarized in Table 1) including coronaviruses (see below). The potency against any particular virus varies for different peptides; for example, the potency of LL-37 for IAV inhibition has been found to be similar to that of HNPs, greater than that of human $\beta$-defensins, but less than that of retrocyclins (Tripathi et al., 2013; Doss et al., 2009). The mode of action of AMPs for these viruses (Table 1) may also differ between types ( $\alpha$ - or $\beta$-) and subtypes (HNP1-4, HD5, HD6; hBD1-4) of defensins, and between defensins and LL-37 (Park et al., 2018; Brice and Diamond, 2020; Chessa et al., 2020); however, the most common antiviral mode of action, in vitro, is the capacity of AMPs to destabilize the viral envelope on contact, damaging the virions and inhibiting infectivity (Currie et al., 2013; Tripathi et al., 2014; Currie et al., 2016; Harcourt et al., 2016).

\section{Antimicrobial Peptides and Their Derivatives: Activities Against Coronaviruses}

All coronaviruses, including SARS-CoV-2, contain four structural proteins, known as the $\mathrm{S}$ (spike), E (envelope), $\mathrm{M}$ (membrane), and $\mathrm{N}$ (nucleocapsid) proteins (Siu et al., 2008; Yoshimoto, 2020). Among these, the most pertinent to studies of 
TABLE 1 | Modes of action of defensins and LL-37 against respiratory viruses.

\begin{tabular}{|c|c|c|}
\hline Viruses & AMPs & Modes of action \\
\hline \multirow[t]{6}{*}{ IAV } & HNP1 & $\begin{array}{l}\text {-Aggregates IAV and enhances neutrophil-mediated clearance [Hartshorn et al. (2006), Tecle et al. (2007), Doss et al. (2009)] } \\
\text {-Inhibits IAV replication through the inhibition of protein kinase C (PKC) in infected cells [Salvatore et al. (2007)] }\end{array}$ \\
\hline & HD5 & •Aggregates IAV and enhances neutrophil-mediated clearance [Tecle et al. (2007); Doss et al. (2009)] \\
\hline & hBD-2 & \\
\hline & hBD-3 & •Blocks viral fusion by creating a protective barrier of immobilized surface glycoproteins [Leikina et al. (2005)] \\
\hline & Retrocyclin & $\bullet$ Aggregates IAV [Doss et al. (2009)] \\
\hline & LL-37 & •Causes disruption of viral membranes [Tripathi et al. (2013)] \\
\hline \multirow[t]{3}{*}{ RSV } & hBD-2 & •Blocks viral entry by destabilizing/disintegrating the viral envelope [Kota et al. (2008)] \\
\hline & LL-37 & -Inhibits new infectious particles and diminishes the spread of infection [Currie et al. (2013)] \\
\hline & & •Directly damages the viral envelope and disrupts viral particles [Currie et al. (2016)] \\
\hline HAdV & HD5 & •Blocks viral-mediated endosomal penetration [Smith and Nemerow (2008)] \\
\hline HRV & LL-37 & -Promotes reduction of the metabolic activity of infected cells [Sousa et al. (2017)] \\
\hline
\end{tabular}

AMP-related activities against coronaviruses is the $\mathrm{S}$ protein. It comprises two functional subunits, i.e., S1 and S2 (Tortorici and Veesler, 2019), where S1 binds to host cell receptor angiotensin converting enzyme 2 (ACE2), followed by fusion of the viral and cellular membranes via S2 (Hoffmann et al., 2020). $\beta$-Defensins and LL-37 naturally serve as antimicrobials at vulnerable mucosal sites of our body and are primed to function as "disruptors" of viral attachment, entry, and infection. With demonstrated diverse mechanisms of action against multiple different viruses including respiratory viruses, these AMPs are obvious candidates to explore as possible anti-SARS-CoV-2 agents. In addition to their central role in innate immunity, it is becoming clear that AMPs can modulate the adaptive immune response as well (Scott et al., 2002; Diamond et al., 2009; Semple and Dorin, 2012; Koeninger et al., 2020; Liang and Diana, 2020), and several studies have demonstrated adjuvant activities of AMPs in vivo (Tani et al., 2000; Biragyn et al., 2002; Brogden et al., 2003; Kohlgraf et al., 2010; Mei et al., 2012). The section below will focus on evidence that AMPs and their smaller peptide derivatives have demonstrated in vitro and in vivo anti-coronaviral activity and set the stage for their consideration as antagonists of SARSCoV-2.

\section{Direct and Indirect Actions of Antimicrobial Peptides}

An in silico study conducted by Mustafa et al. (2019) showed that a short peptide, referred to as $\mathrm{P} 9$, derived from mouse $\beta$-defensin 4 (an ortholog of hBD-2 (Jia et al., 2000)) binds to the type I transmembrane glycoprotein S2 domain of MERS-CoV. An in vivo study by Zhao $\mathrm{H}$. et al. (2016) demonstrated that the P9 peptide has broad-spectrum antiviral activity against different subtypes of IAV, as well as two coronaviruses, SARS-CoV and MERS-CoV. The half-maximal inhibitory concentration $\left(\mathrm{IC}_{50}\right)$ values of P9 against both SARS-CoV and MERS-CoV were $\sim 5 \mu \mathrm{g} / \mathrm{ml}$. One dose of P9 for prophylaxis and five doses of P9 for therapy significantly inhibited SARS-CoV infection in mouse lungs, and the antiviral activity of P9 was attributed to its binding to the viral S2 protein, confirming the in silico work of Mustafa et al. (2019). Moreover, the abundance of basic amino acids in P9's composition prevented acidification in endosomes and inhibited viral RNA release. Recently, Zhao et al. (2020) demonstrated that another short peptide, P9R, which has more net positive charge ( +5.6 compared to +4.7 of P9), inhibits not only MERS-CoV and SARS-CoV but also SARS-CoV-2 ( $\mathrm{IC}_{50}$ values: $2.2,2.4$, and $0.9 \mu \mathrm{g} / \mathrm{ml}$, respectively). P9R was also shown to significantly inhibit SARS-CoV-2 replication when Vero E6 cells were infected with SARS-CoV-2, 6 and $24 \mathrm{~h}$ prior to the addition of P9R (Zhao et al., 2020).

Rhesus $\theta$-defensin 1 (RTD-1) (Lehrer et al., 2012) showed efficacy as a prophylactic antivirus in a mouse model of severe SARS-CoV-induced lung disease (Wohlford-Lenane et al., 2009). $\mathrm{BALB} / \mathrm{c}$ mice exposed to a mouse-adapted strain of SARS-CoV demonstrated $100 \%$ survival and reduction in lung pathology when treated with two intranasal doses of RTD-1, while mortality in untreated mice was $\sim 75 \%$. RTD-1-treated SARS$\mathrm{CoV}$-infected mice displayed reductions in levels of RANTES, IL-1 $\alpha$, IL-1 $\beta$, IL-6, IL-12, and monocyte chemoattractant protein 1a (MCP-1a), compared to untreated SARS-CoV-infected mice (Wohlford-Lenane et al., 2009).

\section{Antimicrobial Peptides as Viral Binding Inhibitors That Can Block CoV-2 Entry}

Multiple therapeutic approaches are currently being considered in attempts to block the CoV-2 S:ACE2 interaction to avoid viral fusion with the cell's membrane and entry into the cell (Whisenant and Burgess, 2020). The intestinal a-defensin HD5, released from Paneth cells in the crypts of the small intestine, was recently found to bind ACE2 in a study conducted by Wang C. et al. (2020). The authors reported that HD5 bound to several ACE2 sites crucial for binding to the S protein-receptor-binding domain (S-RBD) of CoV-2 and demonstrated proof of principle by showing that HD5 blocked $S$ protein-expressing pseudovirions from entering ACE2expressing enterocytes. The authors surmised that this could represent innate protection of intestinal cells against CoV-2 infection.

Recent in silico molecular docking studies predicted strong binding interactions of LL-37 (Lokhande et al., 2020) and hBD-2 (Zhang L et al., 2021) with the receptor-binding domain (RBD) of SARS-CoV-2, suggesting an RBD blocking potential for these two peptides. Biophysical assays using bio-layer interferometry (BLI) and microscale thermophoresis (MST) supported the in silico findings for LL-37 (Wang C. et al., 2021) and hBD-2 (Zhang L. 
et al., 2021), respectively. Additionally, biochemical studies with hBD-2 showed that it inhibited the RBD from binding ACE2 and prevented $S$ protein-expressing pseudovirions from infecting ACE2-expressing human cells (Zhang L. et al., 2021).

Interestingly, LL-37 has been found to suppress $S$ pseudovirion infection in a dose-dependent manner with an $\mathrm{IC}_{50}$ value of $1.05 \mu \mathrm{M}$ (Wang C. et al., 2021). By using a clever in vivo model that incorporated ACE2-expressing adenovirions, either with or without $\mathrm{S}$ protein-expressing pseudovirions, Wang J. et al. (2021) were able to show that intranasal administration of LL-37 protected mice from pulmonary infection (Wang C. et al., 2021). This is the first demonstration of a natural AMP that can inhibit CoV-2 entry via a dual mechanism.

It is important to note that while the focus on blocking SARSCoV-2 entry into vulnerable cells is via ACE2, a new discovery highlights that neuropilin-1 (NRP1), a receptor involved in multiple physiological processes and expressed on many cell types (Roy et al., 2017), is being utilized by the virus to facilitate entry and infection (Cantuti-Castelvetri et al., 2020; Daly et al., 2020). Teesalu et al. (2009) showed that a peptide with an internal R/KXXR/K motif can bind to NRP1 (Teesalu et al., 2009). Interestingly, both hBD-2 and -3 have these motifs near their respective C-terminal ends (KCCK for hBD-2 and KCCR for hBD-3) (Yamaguchi et al., 2002). Therefore, we cannot rule out the possibility of defensins binding to NRP1. However, time will tell if defensins are effective in blocking viral entry via NRP1.

\section{Antimicrobial Peptides as Adjuvants}

hBD-2 and -3 have previously been used as adjuvants to design multi-epitope vaccines against MERS-CoV, utilizing several in silico methods and tools (Srivastava et al., 2018). Kim et al. (2018) found that C57BL/6 mice immunized with hBD-2 conjugated to MERS-CoV-S-RBD (hBD-2/MERS-CoV-S$\mathrm{RBD}$ ) had significantly higher S-RBD-specific IgG titer levels in comparison with those receiving $\mathrm{S}-\mathrm{RBD}$ alone. When hBD2/MERS-CoV-S-RBD was used to treat THP-1 monocytic cells, the expression levels of classical antiviral (IFN- $\beta$, IFN- $\gamma$, PKR, and RNaseL) and primary immune-inducing molecules (NOD2, TNF- $\alpha$, IL-1 $\beta$, and IL-6) were enhanced compared to expression levels after treatment with only S-RBD. The receptor-binding inhibition assay on the MERSCoV-susceptible Vero E6 cell line using sera obtained from mice immunized with PBS, S-RBD, or hBD-2/MERS-CoV-SRBD showed that sera from hBD-2-conjugated S-RBD-inoculated mice almost completely inhibited S-RBD binding to cell surfaces compared with sera from mice immunized with S-RBD alone. hBD-2-conjugated S-RBD was also superior to unconjugated $\mathrm{S}-\mathrm{RBD}$ in inducing neutralizing antibodies against MERS-CoV infection. A more recent study showed that immunization with S RBD-hBD-2 alleviated progressive pulmonary fibrosis in the lungs of MERS$\mathrm{CoV}$-infected mice and suppressed endoplasmic reticulum stress signaling activation upon viral infection (Kim et al., 2020).

A multi-epitope vaccine against SARS-CoV-2 using hBD-3 conjugated to B-cell, helper T-lymphocyte (HTL), and cytotoxic T-lymphocyte (CTL) epitopes was designed using in silico structural biology and immunoinformatic approaches (Whisenant and Burgess, 2020). When tested using the C-ImmSim server (Rapin et al., 2010), which simulates the natural immune outcome, the multi-epitope vaccine generated a robust response by $\mathrm{B}$-cells, $\mathrm{T}$ helper cells, cytotoxic $\mathrm{T}$ cells, and IgG (Ojha et al., 2020). While in silico findings suggest that this vaccine (Ojha et al., 2020) and others using hBD-3 as the adjuvant (Dong et al., 2020; Yazdani et al., 2020) are promising potential therapeutic approaches against COVID-19, in vivo studies need to be conducted to prove their effectiveness against COVID-19.

\section{Vitamin D Deficiency and COVID-19: A Possible Link With Antimicrobial Peptides}

The genes encoding the $\beta$-defensins and LL-37 contain consensus vitamin $\mathrm{D}_{3}$ (Vit $\mathrm{D}_{3}$ ) response elements (VREs) (Wang et al., 2004; McMahon et al., 2011; Aguilar-Jimenez et al., 2013), and it is well established that Vit $\mathrm{D}_{3}$ and its metabolite 1,25-dihydroxy-vitamin $\mathrm{D}_{3}$ regulate the AMPs' expressions (Wang et al., 2004; Adams et al., 2009). Vit $\mathrm{D}_{3}$ deficiencies have been associated with an increase in inflammatory cytokines and significant susceptibility to pneumonia and upper respiratory tract infections (Weir et al., 2020); both are common outcomes in severely ill COVID-19 patients (Chen et al., 2020; Ding et al., 2020; Leisman et al., 2020). Indeed, several studies suggest that Vit $\mathrm{D}_{3}$ may have beneficial properties against SARS-CoV-2, as individuals deficient in $\mathrm{Vit} \mathrm{D}_{3}$ appear to be more susceptible to contracting the virus than those whose levels are normal (Arvinte et al., 2020; Hernández et al., 2020; Kaufman et al., 2020; Radujkovic et al., 2020). Additionally, reduced levels of VREs (important in AMP induction (McMahon et al., 2011; Aguilar-Jimenez et al., 2013)) in cells isolated from bronchoalveolar lavage were found in patients infected with CoV-2 than healthy subjects (George et al., 2020). Moreover, the fact that LL-37 (Zhang et al., 2020) and hBD-2 (Zhang L. et al., 2021), both regulated through Vit $\mathrm{D}_{3}$, were able to block $\mathrm{S}$ protein-expressing pseudovirions from infecting vulnerable human cells supports the notion that healthy levels of $\mathrm{Vit} \mathrm{D}_{3}$ may be important in reducing the risk of acquiring SARS-CoV-2 infection. However, further studies on the direct correlation between Vit $\mathrm{D}_{3}$ and AMP levels in relation to susceptibility to $\mathrm{CoV}-2$ acquisition are required.

\section{Mesenchymal Stem Cells and COVID-19: Plausible Role for Antimicrobial Peptides}

Among several approaches repurposed to treat COVID-19 patients, human mesenchymal stem cell (hMSC) therapy has recently been reported to contribute to the recovery of severely ill CoV-2-infected patients (Moll et al., 2020; Tsuchiya et al., 2020). With a $100 \%$ survival rate using hMSCs in compassionate use programs to treat severely ill COVID-19 patients (Israeli COVID-19 treatment shows $100 \%$ survival rate-preliminary data, Jerusalem Post), several biotech companies and 
universities are conducting clinical trials to evaluate their respective cell therapy platforms. The mechanisms behind hMSC therapeutic benefits are presently a "black box," although some evidence points to the ability of these cells to modulate severe inflammation by secreting several beneficial agents (Iannaccone et al., 2020; Rajarshi et al., 2020; Tsuchiya et al., 2020). Supernatants from activated hMSCs kill microbes associated with cystic fibrosis, and cystic fibrotic mice, which otherwise would succumb to microbial infections, survive these challenges by injection of hMSCs (Krasnodembskaya et al., 2010; Sutton et al., 2016; Alcayaga-Miranda et al., 2017; Chow et al., 2020). These favorable outcomes can be partly attributed to hMSC-released AMPs, such as defensins and LL-37 (Krasnodembskaya et al., 2010; Sutton et al., 2016), which are found in bronchial alveolar lavage (Ghosh et al., 2007; Golec et al., 2012). Do AMPs actually contribute to cessation of inflammation currently attributed to hMSC activity, in addition to directly inhibiting viral infection or not? With growing evidence that defensins and LL-37 have anti-inflammatory properties (Choi et al., 2012; Mansour et al., 2014; Brook et al., 2016), along with their diverse strategies to directly attack viruses, it will be a tall order to dissect out the inflammomodulatory role that hMSCrelated AMPs play in cessation of the cytokine storm that afflicts severely ill CoV-2-infected patients. Finding the right balance of anti-inflammatory vs. pro-inflammatory activities, so that we do not inadvertently exacerbate an already inflamed situation, will require in depth testing of each AMP. These could include determining conformational status, identifying the distinct isoform and amino acid motifs important for each modulatory activity, and designing novel synthetic derivatives from modifications of natural AMPs to then test in both in vitro and in vivo models. This has been an approach espoused by Robert Hancock's group, which they address in a review article (Haney et al., 2019). Moreover, hMSC-related AMPs, which could include additional yet-to-be-discovered peptides, could be interacting in synergy with other beneficial agents secreted by hMSCs, such as exosomal agents that limit immune thrombosis, increase fibrinolytic activity, re-stabilize endothelial integrity, reduce lymphocyte trafficking, and promote recruitment of M2 macrophages and regulatory T cells (Gomzikova et al., 2019; Jamshidi et al., 2021; Moradinasab et al., 2021; Su et al., 2021).

\section{CONCLUSION AND PERSPECTIVES}

The saying that "desperate diseases call for desperate treatments" (attributed to Hippocrates) cannot be more appropriate during these trying times when a worldwide pandemic is wreaking havoc on mankind. It is clear that naturally occurring AMPs, such as defensins and LL-37, possess favorable properties that make them prime candidates for novel anti-COVID-19 therapeutics. They can act directly and indirectly against coronaviruses (WohlfordLenane et al., 2009; Zhao G. et al., 2016; Zhang et al., 2020; Zhao et al., 2020), and they are especially effective at blocking viral entry into vulnerable cells (Wang R.et al., 2020), small peptide derivatives (Zhao et al., 2020), and non-peptide mimetics
(Bakovic et al., 2020). Of these, AMPs are emerging as promising drug candidates, and they can be used as adjuvants (Kim et al., 2018; Dong et al., 2020; Ojha et al., 2020) in vaccines targeting coronaviruses. Additionally, the importance of $\mathrm{Vit} \mathrm{D}_{3}$ in protection against SARS-CoV-2 acquisition and the repurposed use of hMSCs in treating severe cases of COVID-19 point to the possible benefits of AMP protection. Importantly, designing small peptides from human AMPs has multiple advantages. They possess safety, i.e., limiting the need for phase 1 studies, they are highly specific, they could be designed to resist peptidase biodegradability, they are not expensive to produce, and they could be administered easily (Greber and Dawgul, 2017; Di et al., 2020; Luong et al., 2020). Currently, more than 30 AMPs including LL-37 are in clinical and preclinical trials for their potential applications against various infectious diseases (Koo and Seo, 2019).

Several conventional therapeutic drugs, including but not limited to antimalarial drugs, protease inhibitors, renin-angiotensin system (RAS) inhibitors, inhibitors of the RNA-dependent RNA polymerase, and immune suppressants, are being repurposed for the treatment of COVID-19 (Khavinson et al., 2020; Spaccarotella et al., 2021). However, peptide-based therapeutic drugs including AMPs are sometimes a better choice than conventional drugs due to their higher efficacy, lower molecular weight, and lower toxicity and side effects (Castel et al., 2011). Among peptide-based therapeutic drugs, AMPrelated small peptide derivatives (Zhao et al., 2020) and nonpeptide mimetics (Bakovic et al., 2020) are emerging as promising drug candidates. Several potential SARS-CoV-2 entry inhibitor peptides, and strategies used to design those peptides targeting the ACE2 receptor or the viral spike protein and its activating proteases, have been outlined in a recent review by Schütz et al. (2020). Additionally, peptoid mimics (sequence-specific $N$-substituted glycine oligomers) of AMPs and an antimicrobial DP7 peptide (VQWRIRVAVIRK) were recently shown to have anti-CoV-2 activity (Zhang R. et al., 2021; Diamond et al., 2021). Moreover, a synthetic mimetic of defensins, Brilacidin, has been shown to potently inhibit CoV2 in an ACE2-positive human lung cell line (Bakovic et al., 2021) and recently received approval by the Federal Drug Administration (FDA) to start a phase 2 clinical trial in COVID-19 patients (ClinicalTrials.gov; Identifier: NCT04784897).

Since AMPs are highly sensitive to environmental conditions, such as $\mathrm{pH}$ and ionic strength, which often leads to discrepancies between in vitro and in vivo results (Mahlapuu et al., 2016), improving them as viable therapeutics is being addressed through peptide mimetics (Pachón-Ibáñez et al., 2017; Mookherjee et al., 2020). These are being engineered, using the AMP backbone, to increase cationicity and amphipathicity, when needed, with minimal cytotoxicity; for example, a number of shorter LL-37 variants have been generated to improve the antimicrobial activity and reduce the toxicity (Tripathi et al., 2015; PachónIbáñez et al., 2017). Low metabolic stability of AMPs, an additional challenge for therapeutics, is being addressed by modifying the peptide backbone through incorporation of D-amino acids, end-tagging by hydrophobic amino acid 


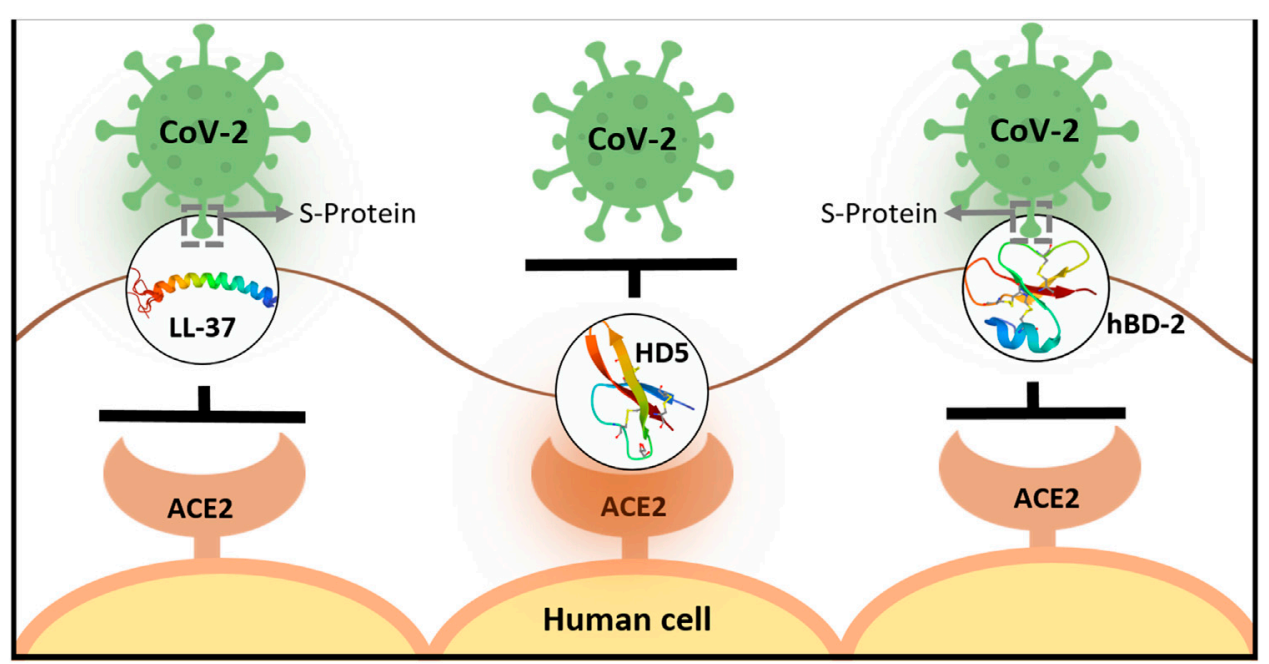

FIGURE 1 | Schematic representation showing differential binding of human AMPs to SARS-CoV-2 S protein or ACE2 on cell surfaces. LL-37 and hBD-2 bind to SARS-CoV-2 S protein and inhibit its binding to ACE2 on the cell surface prior to entry (Lokhande et al., 2020; Roth et al., 2020; Wang C. et al., 2021; Zhang L. et al. 2021). In contrast, HD-5 binds to ACE2 to inhibit viral entry (Wang et al., 2020a) [LL-37 has also been shown to bind ACE2, however, with lower affinity than S-RBD (Wang C. et al., 2021)].

stretches, and blocking $\mathrm{N}$ - and/or C-terminal ends of the peptide by $\mathrm{N}$-acetylation or C-amidation (Zhao Y. et al., 2016; Håkansson et al., 2019; Mahlapuu et al., 2020).

The nasal cavity and nasopharynx contain some of the highest viral loads in the body, and viral load levels are similar in symptomatic and asymptomatic individuals. The so-called "silent spreaders" may involuntarily contribute to the exponential growth of disease, as nasal secretions contain spreadable virus (Higgins et al., 2020) but lack endogenous expression of some of the AMPs [e.g., hBD-2 (Guaní-Guerra et al., 2011; Bouloukaki et al., 2011)]. Additionally, nasopharyngeal swab samples have revealed that CoV2-infected patients have lower mRNA levels of several defensins when compared to uninfected subjects (Idris et al., 2020). To "ramp up" AMP levels, AMPs and/or their derivatives could be administered intranasally and/or intraorally as prophylactic aerosols, in early stages of infection when telltale symptoms begin to appear and in combinatorial therapeutic approaches for more severe situations. A prophylactic strategy has been proposed by Park et al. (2018), when natural endogenous levels of constitutive or viral-induced defensins provide a limited level of defense against infecting viruses, especially with high viral loads. AMP-based therapy has additional benefits in the context of COVID-19, as different AMPs have affinities for different CoV-2 targets; for example, LL-37 (Lokhande et al., 2020; Roth et al., 2020) and hBD-2 (Zhang L. et al., 2021) bind to SARS-CoV-2 S-RBD, whereas HD5 binds to ACE2 (Wang C. et al., 2020) but not SARS-CoV-2 S-RBD [summarized in Figure 1]. Therefore, combining different AMPs that bind different targets associated with CoV-2 entry may turn out to be more beneficial than using only one AMP. Moreover, if mutations in the S-RBD (Wang et al., 2020b) preclude using a specific AMP, other AMPs targeting ACE2 could continue to block viral entry. Additionally, since AMPs and their small peptide derivatives lack immunogenicity and demonstrate low levels of toxicity (Otte et al., 2008; Warnke et al., 2013; Leelakanok et al., 2015), they are ideal candidates for both prophylactic and therapeutic approaches in dealing with SARS-CoV-2 dispersion.

We believe AMP utilization as first-line antivirals is a cogent stopgap while several vaccine candidates are being tested. Moreover, we do not see them diminishing in importance once vaccines are available to everyone, as vaccines do not always provide $100 \%$ protection (Goodwin et al., 2006; Ovsyannikova et al., 2017). Many people will refuse vaccination (Schwarzinger et al., 2010; Fisher et al., 2020; Pogue et al., 2020; Wang J. et al., 2021), and a significant number will fail to mount either effective neutralizing antibodies or high enough titers (Goodwin et al., 2006; Ndifon et al., 2009; Ovsyannikova et al., 2017). Additionally, within a few months since its appearance, CoV-2 has already developed a substantial number of mutations in the receptorbinding motif (RBM) of the RBD (Wang et al., 2020b; Abdool Karim and de Oliveira, 2021; Greaney et al., 2021). Though most mutated variants with amino acid change within the RBD were found to be less infectious, some variants have already become resistant to some neutralizing antibodies (Li et al., 2020; Hoffmann et al., 2021), warranting alternative and adjunctive approaches. There is also evidence of declining levels of neutralizing antibodies in COVID-19 patients within two to three months after recovery (Long et al., 2020; Seow et al., 2020). Given the enormity of the COVID pandemic, it is imperative to develop effective interventions capable of preventing transmission of diverse SARS-CoV-2 variants by exploiting all the possible strategies. 


\section{AUTHOR CONTRIBUTIONS}

SG and AW conceived the idea. SG wrote the original draft. AW revised the manuscript. Both the authors approved the final version.

\section{REFERENCES}

Abdool Karim, S. S., and de Oliveira, T. (2021). New SARS-CoV-2 Variants Clinical, Public Health, and Vaccine Implications. N. Engl. J. Med. 384 (19), 1866-1868. doi:10.1056/nejmc2100362

Adams, J. S., Ren, S., Liu, P. T., Chun, R. F., Lagishetty, V., Gombart, A. F., et al. (2009). Vitamin D-Directed Rheostatic Regulation of Monocyte Antibacterial Responses. J. Immunol. 182 (7), 4289-4295. doi:10.4049/jimmunol.0803736

Aguilar-Jimenez, W., Zapata, W., Caruz, A., and Rugeles, M. T. (2013). High Transcript Levels of Vitamin D Receptor Are Correlated with Higher mRNA Expression of Human Beta Defensins and IL-10 in Mucosa of HIV-1-Exposed Seronegative Individuals. PLoS One 8 (12), e82717. doi:10.1371/ journal.pone.0082717

Ahmed, A., Siman-Tov, G., Hall, G., Bhalla, N., and Narayanan, A. (2019). Human Antimicrobial Peptides as Therapeutics for Viral Infections. Viruses 11 (8):704. doi:10.3390/v11080704

Ahmed, A., Siman-Tov, G., Keck, F., Kortchak, S., Bakovic, A., Risner, K., et al. (2019). Human Cathelicidin Peptide LL-37 as a Therapeutic Antiviral Targeting Venezuelan Equine Encephalitis Virus Infections. Antiviral Res. 164, 61-69. doi:10.1016/j.antiviral.2019.02.002

Alcayaga-Miranda, F., Cuenca, J., and Khoury, M. (2017). Antimicrobial Activity of Mesenchymal Stem Cells: Current Status and New Perspectives of Antimicrobial Peptide-Based Therapies. Front. Immunol. 8, 339. doi:10.3389/fimmu.2017.00339

Arvinte, C., Singh, M., and Marik, P. E. (2020). Serum Levels of Vitamin C and Vitamin D in a Cohort of Critically Ill COVID-19 Patients of a North American Community Hospital Intensive Care Unit in May 2020: A Pilot Study. Med. Drug Discov. 8, 100064. doi:10.1016/j.medidd.2020.100064

Bakovic, A., Risner, K., Bhalla, N., Alem, F., Chang, T. L., Weston, W., et al. (2020) Brilacidin, a COVID-19 Drug Candidate, Exhibits Potent In Vitro Antiviral Activity against SARS-CoV-2. bioRxiv.doi:10.3389/29.352450

Bakovic, A., Risner, K., Bhalla, N., Alem, F., Chang, T. L., Weston, W. K., et al. (2021). Brilacidin Demonstrates Inhibition of SARS-CoV-2 in Cell Culture. Viruses 13 (2). doi:10.3390/v13020271

Barlow, P. G., Svoboda, P., Mackellar, A., Nash, A. A., York, I. A., Pohl, J., et al. (2011). Antiviral Activity and Increased Host Defense against Influenza Infection Elicited by the Human Cathelicidin LL-37. PLoS One 6 (10), e25333. doi:10.1371/journal.pone.0025333

Biragyn, A., Ruffini, P. A., Leifer, C. A., Klyushnenkova, E., Shakhov, A., Chertov, O., et al. (2002). Toll-Like Receptor 4-Dependent Activation of Dendritic Cells by -Defensin 2. Science 298 (5595), 1025-1029. doi:10.1126/science.1075565

Boncristiani, H. F., Criado, M. F., and Arruda, E. (2009). "Respiratory Viruses," in Encyclopedia of Microbiology. Editor M. Schaechter. Third Edition (Oxford: Academic Press), 500-518. doi:10.1016/b978-012373944-5.00314-x

Bouloukaki, I., Tsiligianni, I. G., Tsoumakidou, M., Mitrouska, I., Prokopakis, E. P., Mavroudi, I., et al. (2011). Sputum and Nasal Lavage Lung-specific Biomarkers before and after Smoking Cessation. BMC Pulm. Med. 11, 35. doi:10.1186/14712466-11-35

Brice, D. C., and Diamond, G. (2020). Antiviral Activities of Human Host Defense Peptides. Cmc 27 (9), 1420-1443. doi:10.2174/0929867326666190805151654

Brogden, K. A. (2005). Antimicrobial Peptides: Pore Formers or Metabolic Inhibitors in Bacteria?. Nat. Rev. Microbiol. 3 (3), 238-250. doi:10.1038/ nrmicro1098

Brogden, K. A., Heidari, M., Sacco, R. E., Palmquist, D., Guthmiller, J. M., Johnson, G. K., et al. (2003). Defensin-induced Adaptive Immunity in Mice and its Potential in Preventing Periodontal Disease. Oral Microbiol. Immunol. 18 (2), 95-99. doi:10.1034/j.1399-302x.2003.00047.x

Brook, M., Tomlinson, G. H., Miles, K., Smith, R. W. P., Rossi, A. G., Hiemstra, P. S., et al. (2016). Neutrophil-derived Alpha Defensins Control Inflammation by

\section{FUNDING}

The funds obtained from the Department of Biological Sciences, School of Dental Medicine, Case Western Reserve University, assisted in conducting the study.

Inhibiting Macrophage mRNA Translation. Proc. Natl. Acad. Sci. USA 113 (16), 4350-4355. doi:10.1073/pnas.1601831113

Cantuti-Castelvetri, L., Ojha, R., Pedro, L. D., Djannatian, M., Franz, J., Kuivanen, S., et al. (2020). Neuropilin-1 Facilitates SARS-CoV-2 Cell Entry and Infectivity. Science, 370(6518):856-860. doi:10.1126/science.abd2985

Castel, G., Chtéoui, M., Heyd, B., and Tordo, N. (2011). Phage Display of Combinatorial Peptide Libraries: Application to Antiviral Research. Molecules 16 (5), 3499-3518. doi:10.3390/molecules16053499

Chairatana, P., and Nolan, E. M. (2017). Human a-Defensin 6: A Small Peptide that Self-Assembles and Protects the Host by Entangling Microbes. Acc. Chem. Res. 50 (4), 960-967. doi:10.1021/acs.accounts.6b00653

Chen, L. D., Zhang, Z. Y., Wei, X. J., Cai, Y. Q., Yao, W. Z., Wang, M. H., et al. (2020). Association between Cytokine Profiles and Lung Injury in COVID-19 Pneumonia. Respir. Res. 21 (1), 201. doi:10.1186/s12931-020-01465-2

Chessa, C., Bodet, C., Jousselin, C., Wehbe, M., Lévêque, N., and Garcia, M. (2020). Antiviral and Immunomodulatory Properties of Antimicrobial Peptides Produced by Human Keratinocytes. Front. Microbiol. 11, 1155. doi:10.3389/ fmicb.2020.01155

Choi, K. Y., Chow, L. N., and Mookherjee, N. (2012). Cationic Host Defence Peptides: Multifaceted Role in Immune Modulation and Inflammation. J. Innate Immun. 4 (4), 361-370. doi:10.1159/000336630

Chow, L., Johnson, V., Impastato, R., Coy, J., Strumpf, A., and Dow, S. (2020). Antibacterial Activity of Human Mesenchymal Stem Cells Mediated Directly by Constitutively Secreted Factors and Indirectly by Activation of Innate Immune Effector Cells. STEM CELLS Translational Med. 9 (2), 235-249. doi:10.1002/ sctm.19-0092

Currie, S. M., Findlay, E. G., McHugh, B. J., Mackellar, A., Man, T., Macmillan, D., et al. (2013). The Human Cathelicidin LL-37 Has Antiviral Activity against Respiratory Syncytial Virus. PLoS One 8 (8), e73659. doi:10.1371/ journal.pone.0073659

Currie, S. M., Gwyer Findlay, E., McFarlane, A. J., Fitch, P. M., Böttcher, B., Colegrave, N., et al. (2016). Cathelicidins Have Direct Antiviral Activity against Respiratory Syncytial Virus In Vitro and Protective Function In Vivo in Mice and Humans. J.I. 196 (6), 2699-2710. doi:10.4049/jimmunol.1502478

Daly, J. L., Simonetti, B., Klein, K., Chen, K-E., Williamson, M. K., Antón-Plágaro, C., et al. (2020). Neuropilin-1 Is a Host Factor for SARS-CoV-2 Infection. Science, 370(6518):861-865. doi:10.1126/science.abd3072

Denny, F. W., Jr. (1995). The Clinical Impact of Human Respiratory Virus Infections. Am. J. Respir. Crit. Care Med. 152 (4 Pt 2), S4-S12. doi:10.1164/ ajrccm/152.4_pt_2.s4

Di, Y. P., Lin, Q., Chen, C., Montelaro, R. C., Doi, Y., and Deslouches, B. (2020). Enhanced Therapeutic index of an Antimicrobial Peptide in Mice by Increasing Safety and Activity against Multidrug-Resistant Bacteria. Sci. Adv. 6 (18), eaay6817. doi:10.1126/sciadv.aay6817

Diamond, G., Molchanova, N., Herlan, C., Fortkort, J. A., Lin, J. S., Figgins, E., et al. (2021). Potent Antiviral Activity against HSV-1 and SARS-CoV-2 by Antimicrobial Peptoids. Pharmaceuticals (Basel) 14 (4). doi:10.3390/ ph14040304

Diamond, G., Beckloff, N., Weinberg, A., and Kisich, K. (2009). The Roles of Antimicrobial Peptides in Innate Host Defense. Cpd 15 (21), 2377-2392. doi:10.2174/138161209788682325

Ding, X., Xu, J., Zhou, J., and Long, Q. (2020). Chest CT Findings of COVID-19 Pneumonia by Duration of Symptoms. Eur. J. Radiol. 127, 109009. doi:10.1016/ j.ejrad.2020.109009

Dong, R., Chu, Z., Yu, F., and Zha, Y. (2020). Contriving Multi-Epitope Subunit of Vaccine for COVID-19: Immunoinformatics Approaches. Front. Immunol. 11, 1784. doi: $10.3389 /$ fimmu.2020.01784

Doss, M., White, M. R., Tecle, T., Gantz, D., Crouch, E. C., Jung, G., et al. (2009). Interactions of $\alpha-, \beta$-, and $\theta$-Defensins with Influenza A Virus and Surfactant Protein D. J. Immunol. 182 (12), 7878-7887. doi:10.4049/jimmunol.0804049 
Doss, M., White, M. R., Tecle, T., and Hartshorn, K. L. (2010). Human Defensins and LL-37 in Mucosal Immunity. J. Leukoc. Biol. 87 (1), 79-92. doi:10.1189/jlb.0609382

Fisher, K. A., Bloomstone, S. J., Walder, J., Crawford, S., Fouayzi, H., and Mazor, K. M. (2020). Attitudes toward a Potential SARS-CoV-2 Vaccine. Ann. Intern. Med. 173 (12), 964-973. doi:10.7326/m20-3569

Furci, L., Sironi, F., Tolazzi, M., Vassena, L., and Lusso, P. (2007). a-Defensins Block the Early Steps of HIV-1 Infection: Interference with the Binding of Gp120 to CD4. Blood 109 (7), 2928-2936. doi:10.1182/blood-2006-05024489

George, B., Amjesh, R., Paul, A. M., Tr, S. K., Pillai, M. R., and Kumar, R. (2020). Evidence of a Dysregulated Vitamin D Pathway in SARS-CoV-2 Infected Patient's Lung Cells. bioRxiv 11, 8570. doi:10.1038/s41598-021-87703-z

Ghosh, S. K., Gerken, T. A., Schneider, K. M., Feng, Z., McCormick, T. S., and Weinberg, A. (2007). Quantification of Human $\beta$-Defensin-2 and -3 in Body Fluids: Application for Studies of Innate Immunity. Clin. Chem. 53 (4), 757-765. doi:10.1373/clinchem.2006.081430

Golec, M., Reichel, C., Lemieszek, M., Mackiewicz, B., Buczkowski, J., Sitkowska, J., et al. (2012). Cathelicidin LL-37 in Bronchoalveolar Lavage and Epithelial Lining Fluids from COPD Patients and Healthy Individuals. J. Biol. Regul. Homeost Agents 26 (4), 617-625.

Gomzikova, M. O., James, V., and Rizvanov, A. A. (2019). Therapeutic Application of Mesenchymal Stem Cells Derived Extracellular Vesicles for Immunomodulation. Front. Immunol. 10, 2663. doi:10.3389/fimmu.2019.02663

Goodwin, K., Viboud, C., and Simonsen, L. (2006). Antibody Response to Influenza Vaccination in the Elderly: a Quantitative Review. Vaccine 24 (8), 1159-1169. doi:10.1016/j.vaccine.2005.08.105

Greaney, A. J., Starr, T. N., Gilchuk, P., Zost, S. J., Binshtein, E., Loes, A. N., et al. (2021). Complete Mapping of Mutations to the SARS-CoV-2 Spike ReceptorBinding Domain that Escape Antibody Recognition. Cell Host \& Microbe 29 (1), 44-57.e9. doi:10.1016/j.chom.2020.11.007

Greber, K. E., and Dawgul, M. (2017). Antimicrobial Peptides under Clinical Trials. Curr. Top. Med. Chem. 17 (5), 620-628. doi:10.2174/1568026616666160713143331

Guaní-Guerra, E., Negrete-García, M. C., Montes-Vizuet, R., Asbun-Bojalil, J., and Terán, L. M. (2011). Human $\beta$-Defensin-2 Induction in Nasal Mucosa after Administration of Bacterial Lysates. Arch. Med. Res. 42 (3), 189-194. doi:10.1016/j.arcmed.2011.04.003

Håkansson, J., Ringstad, L., Umerska, A., Johansson, J., Andersson, T., Boge, L., et al. (2019). Characterization of the In Vitro, Ex Vivo, and In Vivo Efficacy of the Antimicrobial Peptide DPK-060 Used for Topical Treatment. Front Cel Infect Microbiol 9, 174. doi:10.3389/fcimb.2019.00174

Hancock, R. E. W., Haney, E. F., and Gill, E. E. (2016). The Immunology of Host Defence Peptides: beyond Antimicrobial Activity. Nat. Rev. Immunol. 16 (5), 321-334. doi:10.1038/nri.2016.29

Haney, E. F., Straus, S. K., and Hancock, R. E. W. (2019). Reassessing the Host Defense Peptide Landscape. Front. Chem. 7, 43. doi:10.3389/fchem.2019.00043

Harcourt, J. L., McDonald, M., Svoboda, P., Pohl, J., Tatti, K., and Haynes, L. M. (2016). Human Cathelicidin, LL-37, Inhibits Respiratory Syncytial Virus Infection in Polarized Airway Epithelial Cells. BMC Res. Notes 9, 11. doi:10.1186/s13104-015-1836-y

Hartshorn, K. L., White, M. R., Tecle, T., Holmskov, U., and Crouch, E. C. (2006). Innate Defense against Influenza A Virus: Activity of Human Neutrophil Defensins and Interactions of Defensins with Surfactant Protein D. J. Immunol. 176 (11), 6962-6972. doi:10.4049/jimmunol.176.11.6962

Hernández, J. L., Nan, D., Fernandez-Ayala, M., García-Unzueta, M., HernándezHernández, M. A., López-Hoyos, M., et al. (2020). Vitamin D Status in Hospitalized Patients with SARS-CoV-2 Infection. J. Clin. Endocrinol. Metab. 106(3):e1343-e1353. doi:10.1210/clinem/dgaa733

Higgins, T. S., Wu, A. W., Illing, E. A., Sokoloski, K. J., Weaver, B. A., Anthony, B. P., et al. (2020). Intranasal Antiviral Drug Delivery and Coronavirus Disease 2019 (COVID-19): A State of the Art Review, Otolaryngol. Head Neck Surg. 163. 682-694. doi:10.1177/0194599820933170

Hoffmann, M., Arora, P., Groß, R., Seidel, A., Hörnich, B. F., Hahn, A. S., et al. (2021). SARS-CoV-2 Variants B.1.351 and P.1 Escape from Neutralizing Antibodies. Cell 184 (9), 2384-2393.e12. doi:10.1016/j.cell.2021.03.036

Hoffmann, M., Kleine-Weber, H., Schroeder, S., Krüger, N., Herrler, T., Erichsen, S., et al. (2020). SARS-CoV-2 Cell Entry Depends on ACE2 and TMPRSS2 and Is Blocked by a Clinically Proven Protease Inhibitor. Cell 181 (2), 271-280.e8. doi:10.1016/j.cell.2020.02.052
Iannaccone, G., Scacciavillani, R., Del Buono, M. G., Camilli, M., Ronco, C., Lavie, C. J., et al. (2020). Weathering the Cytokine Storm in COVID-19: Therapeutic Implications. Cardiorenal Med. 10, 277-287. doi:10.1159/000509483

Idris, M. M., Banu, S., Siva, A. B., and Nagaraj, R. (2020). Downregulation of Defensin Genes in SARS-CoV-2 Infection. medRxiv, 2020. doi:10.1101/ 2020.09.21.20195537

Israeli COVID-19 treatment shows 100\% survival rate - preliminary data Jerusalem Post [Available from: https://www.jpost.com/health-science/israeli-covid-19-treatmentshows-100-percent-survival-rate-preliminary-data-624058 (Accessed April 12, 2020).

Jamshidi, E., Babajani, A., Soltani, P., and Niknejad, H. (2021). Proposed Mechanisms of Targeting COVID-19 by Delivering Mesenchymal Stem Cells and Their Exosomes to Damaged Organs. Stem Cel Rev Rep 17 (1), 176-192. doi:10.1007/s12015-020-10109-3

Jia, H. P., Wowk, S. A., Schutte, B. C., Lee, S. K., Vivado, A., Tack, B. F., et al. (2000). A Novel Murine $\beta$-Defensin Expressed in Tongue, Esophagus, and Trachea. J. Biol. Chem. 275 (43), 33314-33320. doi:10.1074/jbc.m006603200

John Hopkins University (2020). Coronavirus Resource Center. Available from: https://coronavirus.jhu.edu/.

Kaufman, H. W., Niles, J. K., Kroll, M. H., Bi, C., and Holick, M. F. (2020). SARSCoV-2 Positivity Rates Associated with Circulating 25-hydroxyvitamin D Levels. PLoS One 15 (9), e0239252. doi:10.1371/journal.pone.0239252

Khavinson, V., Linkova, N., Dyatlova, A., Kuznik, B., and Umnov, R. (2020). Peptides: Prospects for Use in the Treatment of COVID-19. Molecules 25 (19) 4389. doi:10.3390/molecules 25194389

Kim, J., Yang, Y. L., Jang, S. H., and Jang, Y. S. (2018). Human Beta-Defensin 2 Plays a Regulatory Role in Innate Antiviral Immunity and Is Capable of Potentiating the Induction of Antigen-specific Immunity. Virol. J. 15 (1), 124. doi:10.1186/s12985-018-1035-2

Kim, J., Yang, Y. L., Jeong, Y., and Jang, Y. S. (2020). Conjugation of Human $\beta$-Defensin 2 to Spike Protein Receptor-Binding Domain Induces Antigenspecific Protective Immunity against Middle East Respiratory Syndrome Coronavirus Infection in Human Dipeptidyl Peptidase 4 Transgenic Mice. Vaccines (Basel) 8 (4)635. doi:10.3390/vaccines8040635

Koeninger, L., Armbruster, N. S., Brinch, K. S., Kjaerulf, S., Andersen, B., Langnau, C., et al. (2020). Human $\beta$-Defensin 2 Mediated Immune Modulation as Treatment for Experimental Colitis. Front. Immunol. 11, 93. doi:10.3389/ fimmu.2020.00093

Kohlgraf, K. G., Pingel, L. C., Dietrich, D. E., and Brogden, K. A. (2010). Defensins as Anti-inflammatory Compounds and Mucosal Adjuvants. Future Microbiol. 5 (1), 99-113. doi:10.2217/fmb.09.104

Koo, H. B., and Seo, J. (2019). Antimicrobial Peptides under Clinical Investigation. Pept. Sci. 111 (5), e24122. doi:10.1002/pep2.24122

Kota, S., Sabbah, A., Chang, T. H., Harnack, R., Xiang, Y., Meng, X., et al. (2008). Role of Human $\beta$-Defensin-2 during Tumor Necrosis Factor-A/nf-KbMediated Innate Antiviral Response against Human Respiratory Syncytial Virus*. J. Biol. Chem. 283 (33), 22417-22429. doi:10.1074/jbc.m710415200

Krasnodembskaya, A., Song, Y., Fang, X., Gupta, N., Serikov, V., Lee, J.-W., et al. (2010). Antibacterial Effect of Human Mesenchymal Stem Cells Is Mediated in Part from Secretion of the Antimicrobial Peptide LL-37. Stem Cells 28 (12), 2229-2238. doi:10.1002/stem.544

Leelakanok, N., Fischer, C. L., Bates, A. M., Guthmiller, J. M., Johnson, G. K., Salem, A. K., et al. (2015). Cytotoxicity of HBD3 for Dendritic Cells, normal Human Epidermal Keratinocytes, hTERT Keratinocytes, and Primary Oral Gingival Epithelial Keratinocytes in Cell Culture Conditions. Toxicol. Lett. 239 (2), 90-96. doi:10.1016/j.toxlet.2015.09.006

Lehrer, R. I., Cole, A. M., and Selsted, M. E. (2012). $\theta$-Defensins: Cyclic Peptides with Endless Potential. J. Biol. Chem. 287 (32), 27014-27019. doi:10.1074/ jbc.r112.346098

Leikina, E., Delanoe-Ayari, H., Melikov, K., Cho, M.-S., Chen, A., Waring, A. J., et al. (2005). Carbohydrate-binding Molecules Inhibit Viral Fusion and Entry by Crosslinking Membrane Glycoproteins. Nat. Immunol. 6 (10), 995-1001. doi: $10.1038 /$ ni1248

Leisman, D. E., Ronner, L., Pinotti, R., Taylor, M. D., Sinha, P., Calfee, C. S., et al. (2020). Cytokine Elevation in Severe and Critical COVID-19: a Rapid Systematic Review, Meta-Analysis, and Comparison with Other Inflammatory Syndromes. Lancet Respir. Med. 8 (12), 1233-1244. doi:10.1016/s2213-2600(20)30404-5

Leung, N. H. L. (2021). Transmissibility and Transmission of Respiratory Viruses. Nat. Rev. Microbiol., 1-18. doi:10.1038/s41579-021-00535-6 
Li, Q., Wu, J., Nie, J., Zhang, L., Hao, H., Liu, S., et al. (2020). The Impact of Mutations in SARS-CoV-2 Spike on Viral Infectivity and Antigenicity. Cell 182 (5), 1284-1294.e9. doi:10.1016/j.cell.2020.07.012

Liang, W., and Diana, J. (2020). The Dual Role of Antimicrobial Peptides in Autoimmunity. Front. Immunol. 11, 2077. doi:10.3389/fimmu.2020.02077

Lokhande, K. B. B., Tanushree Swamy, K. V., and Deshpande, M. (2020). An in Silico Scientific Basis for LL-37 as a Therapeutic and Vitamin D as Preventive for Covid-19. ChemRxiv. doi:10.26434/chemrxiv.12928202.v2

Long, Q.-X., Tang, X.-J., Shi, Q.-L., Li, Q., Deng, H.-J., Yuan, J., et al. (2020). Clinical and Immunological Assessment of Asymptomatic SARS-CoV-2 Infections. Nat. Med. 26 (8), 1200-1204. doi:10.1038/s41591-020-0965-6

Luong, H. X., Thanh, T. T., and Tran, T. H. (2020). Antimicrobial Peptides Advances in Development of Therapeutic Applications. Life Sci. 260, 118407. doi:10.1016/j.lfs.2020.118407

Mahlapuu, M., Håkansson, J., Ringstad, L., and Björn, C. (2016). Antimicrobial Peptides: An Emerging Category of Therapeutic Agents. Front. Cel Infect Microbiol 6, 194. doi:10.3389/fcimb.2016.00194

Mahlapuu, M., Björn, C., and Ekblom, J. (2020). Antimicrobial Peptides as Therapeutic Agents: Opportunities and Challenges. Crit. Rev. Biotechnol. 40 (7), 978-992. doi:10.1080/07388551.2020.1796576

Mansour, S. C., Pena, O. M., and Hancock, R. E. W. (2014). Host Defense Peptides: Front-Line Immunomodulators. Trends Immunol. 35 (9), 443-450. doi:10.1016/j.it.2014.07.004

McMahon, L., Schwartz, K., Yilmaz, O., Brown, E., Ryan, L. K., and Diamond, G. (2011). Vitamin D-Mediated Induction of Innate Immunity in Gingival Epithelial Cells. Infect. Immun. 79 (6), 2250-2256. doi:10.1128/iai.00099-11

Mei, H. F., Jin, X. B., Zhu, J. Y., Zeng, A. H., Wu, Q., Lu, X. M., et al. (2012). $\beta$-Defensin 2 as an Adjuvant Promotes Anti-melanoma Immune Responses and Inhibits the Growth of Implanted Murine Melanoma In Vivo. PLoS One 7 (2), e31328. doi:10.1371/journal.pone.0031328

Moll, G., Drzeniek, N., Kamhieh-Milz, J., Geissler, S., Volk, H. D., and Reinke, P. (2020). MSC Therapies for COVID-19: Importance of Patient Coagulopathy, Thromboprophylaxis, Cell Product Quality and Mode of Delivery for Treatment Safety and Efficacy. Front. Immunol. 11, 1091. doi:10.3389/fimmu.2020.01091

Mookherjee, N., Anderson, M. A., Haagsman, H. P., and Davidson, D. J. (2020). Antimicrobial Host Defence Peptides: Functions and Clinical Potential. Nat. Rev. Drug Discov. 19 (5), 311-332. doi:10.1038/s41573-019-0058-8

Moradinasab, S., Pourbagheri-Sigaroodi, A., Zafari, P., Ghaffari, S. H., and Bashash, D. (2021). Mesenchymal Stromal/stem Cells (MSCs) and MSC-Derived Extracellular Vesicles in COVID-19-Induced ARDS: Mechanisms of Action, Research Progress, Challenges, and Opportunities. Int. Immunopharmacology 97, 107694. doi:10.1016/j.intimp.2021.107694

GBD 2017 Influenza Collaborators (2019). Mortality, Morbidity, and Hospitalisations Due to Influenza Lower Respiratory Tract Infections, 2017: an Analysis for the Global Burden of Disease Study 2017. Lancet Respir. Med. 7(1):69-89.doi:10.1016/S2213-2600(18)30496-X

Mustafa, S., Balkhy, H., and Gabere, M. (2019). Peptide-Protein Interaction Studies of Antimicrobial Peptides Targeting Middle East Respiratory Syndrome Coronavirus Spike Protein: An In Silico Approach. Adv. Bioinformatics 2019, 6815105. doi:10.1155/2019/6815105

Ndifon, W., Wingreen, N. S., and Levin, S. A. (2009). Differential Neutralization Efficiency of Hemagglutinin Epitopes, Antibody Interference, and the Design of Influenza Vaccines. Proc. Natl. Acad. Sci. 106 (21), 8701-8706. doi:10.1073/pnas.0903427106

Nordenfelt, P., and Tapper, H. (2011). Phagosome Dynamics during Phagocytosis by Neutrophils. J. Leukoc. Biol. 90 (2), 271-284. doi:10.1189/jlb.0810457

Ojha, R., Gupta, N., Naik, B., Singh, S., Verma, V. K., Prusty, D., et al. (2020). High Throughput and Comprehensive Approach to Develop Multiepitope Vaccine against Minacious COVID-19. Eur. J. Pharm. Sci. 151, 105375. doi:10.1016/j.ejps.2020.105375

Otte, J.-M., Werner, I., Brand, S., Chromik, A. M., Schmitz, F., Kleine, M., et al. (2008). Human Beta Defensin 2 Promotes Intestinal Wound Healing In Vitro. J. Cel. Biochem. 104 (6), 2286-2297. doi:10.1002/jcb.21787

Ovsyannikova, I. G., Schaid, D. J., Larrabee, B. R., Haralambieva, I. H., Kennedy, R. B., and Poland, G. A. (2017). A Large Population-Based Association Study between HLA and KIR Genotypes and Measles Vaccine Antibody Responses. PLoS One 12 (2), e0171261. doi:10.1371/journal.pone.0171261

Pachón-Ibáñez, M. E., Smani, Y., Pachón, J., and Sánchez-Céspedes, J. (2017). Perspectives for Clinical Use of Engineered Human Host Defense Antimicrobial Peptides. FEMS Microbiol. Rev. 41 (3), 323-342. doi:10.1093/femsre/fux012
Park, M. S., Kim, J. I., Lee, I., Park, S., Bae, J.-Y., and Park, M.-S. (2018). Towards the Application of Human Defensins as Antivirals. Biomolecules Ther. 26 (3), 242-254. doi:10.4062/biomolther.2017.172

Pogue, K., Jensen, J. L., Stancil, C. K., Ferguson, D. G., Hughes, S. J., Mello, E. J., et al. (2020). Influences on Attitudes Regarding Potential COVID-19 Vaccination in the United States. Vaccines (Basel) 8 (4). doi:10.3390/vaccines8040582

Prasad, S. V., Fiedoruk, K., Daniluk, T., Piktel, E., and Bucki, R. (2019). Expression and Function of Host Defense Peptides at Inflammation Sites. Int. J. Mol. Sci. 21 (1)104. doi:10.3390/ijms21010104

Quiñones-Mateu, M. E., Lederman, M. M., Feng, Z., Chakraborty, B., Weber, J., Rangel, H. R., et al. (2003). Human Epithelial $\beta$-defensins 2 and 3 Inhibit HIV-1 Replication. Aids 17 (16), F39-F48. doi:10.1097/00002030-200311070-00001

Radujkovic, A., Hippchen, T., Tiwari-Heckler, S., Dreher, S., Boxberger, M., and Merle, U. (2020). Vitamin D Deficiency and Outcome of COVID-19 Patients. Nutrients 12 (9). doi:10.3390/nu12092757

Rajarshi, K., Chatterjee, A., and Ray, S. (2020). Combating COVID-19 with Mesenchymal Stem Cell Therapy. Biotechnol. Rep. (Amst). 26, e00467. doi:10.1016/j.btre.2020.e00467

Rapin, N., Lund, O., Bernaschi, M., and Castiglione, F. (2010). Computational Immunology Meets Bioinformatics: the Use of Prediction Tools for Molecular Binding in the Simulation of the Immune System. PLoS One 5 (4), e9862. doi:10.1371/journal.pone.0009862

Roth, A., Lütke, S., Meinberger, D., Hermes, G., Sengle, G., Koch, M., et al. (2020). LL-37 Fights SARS-CoV-2: The Vitamin D-Inducible Peptide LL-37 Inhibits Binding of SARS-CoV-2 Spike Protein to its Cellular Receptor Angiotensin Converting Enzyme 2 In Vitro. bioRxiv. doi:10.1101/2020.12.02.408153

Roy, S., Bag, A. K., Singh, R. K., Talmadge, J. E., Batra, S. K., and Datta, K. (2017). Multifaceted Role of Neuropilins in the Immune System: Potential Targets for Immunotherapy. Front. Immunol. 8, 1228. doi:10.3389/fimmu.2017.01228

Salvatore, M., García-Sastre, A., Ruchala, P., Lehrer, R. I., Chang, T., and Klotman, M. E. (2007). $\alpha$-Defensin Inhibits Influenza Virus Replication by Cell-Mediated Mechanism(s). J. Infect. Dis. 196 (6), 835-843. doi:10.1086/521027

Schütz, D., Ruiz-Blanco, Y. B., Münch, J., Kirchhoff, F., Sanchez-Garcia, E., and Müller, J. A. (2020). Peptide and Peptide-Based Inhibitors of SARS-CoV-2 Entry. Adv. Drug Deliv. Rev. 167, 47-65. doi:10.1016/j.addr.2020.11.007

Schwarzinger, M., Flicoteaux, R., Cortarenoda, S., Obadia, Y., and Moatti, J. P. (2010). Low Acceptability of A/H1N1 Pandemic Vaccination in French Adult Population: Did Public Health Policy Fuel Public Dissonance?. PLoS One 5 (4), e10199. doi:10.1371/journal.pone.0010199

Scott, M. G., Davidson, D. J., Gold, M. R., Bowdish, D., and Hancock, R. E. W. (2002). The Human Antimicrobial Peptide LL-37 Is a Multifunctional Modulator of Innate Immune Responses. J. Immunol. 169 (7), 3883-3891. doi:10.4049/jimmunol.169.7.3883

Semple, F., and Dorin, J. R. (2012). SS-Defensins: Multifunctional Modulators of Infection, Inflammation and More? J. Innate Immun. 4 (4), 337-348. doi:10.1159/000336619

Seow, J., Graham, C., Merrick, B., Acors, S., Pickering, S., Steel, K. J. A., et al. (2020). Longitudinal Observation and Decline of Neutralizing Antibody Responses in the Three Months Following SARS-CoV-2 Infection in Humans. Nat. Microbiol. 5 (12), 1598-1607. doi:10.1038/s41564-020-00813-8

Siu, Y. L., Teoh, K. T., Lo, J., Chan, C. M., Kien, F., Escriou, N., et al. (2008). The M, E, and N Structural Proteins of the Severe Acute Respiratory Syndrome Coronavirus Are Required for Efficient Assembly, Trafficking, and Release of Virus-like Particles. Jvi 82 (22), 11318-11330. doi:10.1128/jvi.01052-08

Smith, J. G., and Nemerow, G. R. (2008). Mechanism of Adenovirus Neutralization by Human a-Defensins. Cell Host \& Microbe 3 (1), 11-19. doi:10.1016/ j.chom.2007.12.001

Soehnlein, O., Kai-Larsen, Y., Frithiof, R., Sorensen, O. E., Kenne, E., ScharffetterKochanek, K., et al. (2008). Neutrophil Primary Granule Proteins HBP and HNP1-3 Boost Bacterial Phagocytosis by Human and Murine Macrophages. J. Clin. Invest. 118 (10), 3491-3502. doi:10.1172/jci35740

Sousa, F. H., Casanova, V., Findlay, F., Stevens, C., Svoboda, P., Pohl, J., et al. (2017). Cathelicidins Display Conserved Direct Antiviral Activity towards Rhinovirus. Peptides 95, 76-83. doi:10.1016/j.peptides.2017.07.013

Spaccarotella, C., Mazzitelli, M., Migliarino, S., Curcio, A., De Rosa, S., Torti, C., et al. (2021). Therapy with RAS Inhibitors during the COVID-19 Pandemic. J. Cardiovasc. Med. (Hagerstown) 22 (5), 329-334. doi:10.2459/ jcm. 0000000000001160 
Srivastava, S., Kamthania, M., Singh, S., Saxena, A., and Sharma, N. (2018). Structural Basis of Development of Multi-Epitope Vaccine against Middle East Respiratory Syndrome Using In Silico Approach. Idr Vol. 11, 2377-2391. doi:10.2147/idr.s175114

Su, N., Hao, Y., Wang, F., Hou, W., Chen, H., and Luo, Y. (2021). Mesenchymal Stromal Exosome-Functionalized Scaffolds Induce Innate and Adaptive Immunomodulatory Responses toward Tissue Repair. Sci. Adv. 7 (20). doi:10.1126/sciadv.abf7207

Suarez-Carmona, M., Hubert, P., Delvenne, P., and Herfs, M. (2015). Defensins: "Simple" Antimicrobial Peptides or Broad-Spectrum Molecules? Cytokine Growth Factor. Rev. 26 (3), 361-370. doi:10.1016/j.cytogfr.2014.12.005

Sutton, M. T., Fletcher, D., Ghosh, S. K., Weinberg, A., van Heeckeren, R., Kaur, S., et al. (2016). Antimicrobial Properties of Mesenchymal Stem Cells: Therapeutic Potential for Cystic Fibrosis Infection, and Treatment. Stem Cell Int 2016, 5303048. doi:10.1155/2016/5303048

Tani, K., Murphy, W. J., Chertov, O., Salcedo, R., Koh, C. Y., Utsunomiya, I., et al. (2000). Defensins Act as Potent Adjuvants that Promote Cellular and Humoral Immune Responses in Mice to a Lymphoma Idiotype and Carrier Antigens. Int. Immunol. 12 (5), 691-700. doi:10.1093/intimm/12.5.691

Tecle, T., White, M. R., Gantz, D., Crouch, E. C., and Hartshorn, K. L. (2007). Human Neutrophil Defensins Increase Neutrophil Uptake of Influenza A Virus and Bacteria and Modify Virus-Induced Respiratory Burst Responses. J. Immunol. 178 (12), 8046-8052. doi:10.4049/jimmunol.178.12.8046

Teesalu, T., Sugahara, K. N., Kotamraju, V. R., and Ruoslahti, E. (2009). C-end Rule Peptides Mediate Neuropilin-1-dependent Cell, Vascular, and Tissue Penetration. Proc. Natl. Acad. Sci. 106 (38), 16157-16162. doi:10.1073/pnas.0908201106

Tortorici, M. A., and Veesler, D. (2019). Structural Insights into Coronavirus Entry. Adv. Virus. Res. 105, 93-116. doi:10.1016/bs.aivir.2019.08.002

Tripathi, S., Tecle, T., Verma, A., Crouch, E., White, M., and Hartshorn, K. L. (2013). The Human Cathelicidin LL-37 Inhibits Influenza A Viruses through a Mechanism Distinct from that of Surfactant Protein D or Defensins. J. Gen. Virol. 94 (Pt 1), 40-49. doi:10.1099/vir.0.045013-0

Tripathi, S., Wang, G., White, M., Qi, L., Taubenberger, J., and Hartshorn, K. L. (2015). Antiviral Activity of the Human Cathelicidin, LL-37, and Derived Peptides on Seasonal and Pandemic Influenza A Viruses. PLoS One 10 (4), e0124706. doi:10.1371/journal.pone.0124706

Tripathi, S., Verma, A., Kim, E.-J., White, M. R., and Hartshorn, K. L. (2014). LL-37 Modulates Human Neutrophil Responses to Influenza A Virus. J. Leukoc. Biol. 96 (5), 931-938. doi:10.1189/jlb.4a1113-604rr

Tsuchiya, A., Takeuchi, S., Iwasawa, T., Kumagai, M., Sato, T., Motegi, S., et al. (2020). Therapeutic Potential of Mesenchymal Stem Cells and Their Exosomes in Severe Novel Coronavirus Disease 2019 (COVID-19) Cases. Inflamm. Regen. 40, 14. doi:10.1186/s41232-020-00121-y

Wang, C., Wang, S., Li, D., Chen, P., Han, S., Zhao, G., et al. (2021). Human Cathelicidin Inhibits SARS-CoV-2 Infection: Killing Two Birds with One Stone. ACS Infect. Dis. acsinfecdis.1c00096. doi:10.1021/acsinfecdis.1c00096

Wang, C., Wang, S., Li, D., Wei, D.-Q., Zhao, J., and Wang, J. (2020). Human Intestinal Defensin 5 Inhibits SARS-CoV-2 Invasion by Cloaking ACE2. Gastroenterology 159 (3), 1145-1147.e4. doi:10.1053/j.gastro.2020.05.015

Wang, J., Feng, Y., Hou, Z., Lu, Y., Chen, H., Ouyang, L., et al. (2021). Willingness to Receive SARS-CoV-2 Vaccine Among Healthcare Workers in Public Institutions of Zhejiang Province, China. Hum. Vaccin. Immunother., 1-8. doi:10.1080/21645515.2021.1909328

Wang, R., Hozumi, Y., Yin, C., and Wei, G. W. (2020). Decoding SARS-CoV-2 Transmission and Evolution and Ramifications for COVID-19 Diagnosis, Vaccine, and Medicine. J. Chem. Inf. Model. 60(12):5853-5865. doi:10.1021/ acs.jcim.0c00501

Wang, T.-T., Nestel, F. P., Bourdeau, V., Nagai, Y., Wang, Q., Liao, J., et al. (2004). Cutting Edge: 1,25-dihydroxyvitamin D3 Is a Direct Inducer of Antimicrobial Peptide Gene Expression. J. Immunol. 173 (5), 2909-2912. doi:10.4049/ jimmunol.173.5.2909

Warnke, P. H., Voss, E., Russo, P. A. J., Stephens, S., Kleine, M., Terheyden, H., et al. (2013). Antimicrobial Peptide Coating of Dental Implants: Biocompatibility Assessment of Recombinant Human Beta Defensin-2 for Human Cells. Int. J. Oral Maxillofac. Implants 28 (4), 982-988. doi:10.11607/jomi.2594
Weir, E. K., Thenappan, T., Bhargava, M., and Chen, Y. (2020). Does Vitamin D Deficiency Increase the Severity of COVID-19?. Clin. Med. 20 (4), e107-e108. doi:10.7861/clinmed.2020-0301

Weston, S., and Frieman, M. B. (2019). "Respiratory Viruses," in Encyclopedia of Microbiology. Editor TM Schmidt. Fourth Edition (Oxford: Academic Press), 85-101.

Whisenant, J., and Burgess, K. (2020). Blocking Coronavirus 19 Infection via the SARS-CoV-2 Spike Protein: Initial Steps. ACS Med. Chem. Lett. 11 (6), 1076-1078. doi:10.1021/acsmedchemlett.0c00233

Wilson, S. S., Wiens, M. E., and Smith, J. G. (2013). Antiviral Mechanisms of Human Defensins. J. Mol. Biol. 425 (24), 4965-4980. doi:10.1016/ j.jmb.2013.09.038

Wohlford-Lenane, C. L., Meyerholz, D. K., Perlman, S., Zhou, H., Tran, D., Selsted, M. E., et al. (2009). Rhesus Theta-Defensin Prevents Death in a Mouse Model of Severe Acute Respiratory Syndrome Coronavirus Pulmonary Disease. Jvi 83 (21), 11385-11390. doi:10.1128/jvi.01363-09

Xhindoli, D., Pacor, S., Benincasa, M., Scocchi, M., Gennaro, R., and Tossi, A. (2016). The Human Cathelicidin LL-37 - A Pore-Forming Antibacterial Peptide and Host-Cell Modulator. Biochim. Biophys. Acta (Bba) - Biomembranes 1858 (3), 546-566. doi:10.1016/j.bbamem.2015.11.003

Yamaguchi, Y., Nagase, T., Makita, R., Fukuhara, S., Tomita, T., Tominaga, T., et al. (2002). Identification of Multiple Novel Epididymis-specific $\beta$-Defensin Isoforms in Humans and Mice. J. Immunol. 169 (5), 2516-2523. doi:10.4049/jimmunol.169.5.2516

Yazdani, Z., Rafiei, A., Yazdani, M., and Valadan, R. (2020). Design an Efficient Multi-Epitope Peptide Vaccine Candidate against SARS-CoV-2: An In Silico Analysis. Idr Vol. 13, 3007-3022. doi:10.2147/idr.s264573

Yoshimoto, F. K. (2020). The Proteins of Severe Acute Respiratory Syndrome Coronavirus-2 (SARS CoV-2 or N-COV19), the Cause of COVID-19. Protein J. 39 (3), 198-216. doi:10.1007/s10930-020-09901-4

Zanetti, M., Gennaro, R., and Romeo, D. (1995). Cathelicidins: a Novel Protein Family with a Common Proregion and a Variable C-Terminal Antimicrobial Domain. FEBS Lett. 374 (1), 1-5. doi:10.1016/0014-5793(95)01050-o

Zhang, H., Zhao, Y., Jiang, X., Zhao, Y., Li, Y., Li, C., et al. (2020). Preliminary Evaluation of the Safety and Efficacy of Oral Human Antimicrobial Peptide LL37 in the Treatment of Patients of COVID-19, a Small-Scale, Single-Arm, Exploratory Safety Study. medRxiv. doi:10.1101/2020.05.11.20064584

Zhang, L., Ghosh, S. K., Basavarajappa, S. C., Muller-Greven, J., Penfield, J., Brewer, A., et al. (2021). Molecular Dynamics Simulations and Functional Studies Reveal that hBD-2 Binds SARS-CoV-2 Spike RBD and Blocks Viral Entry into ACE2 Expressing Cells. bioRxiv, 2021:425621. doi:10.1101/2021.01.07.425621

Zhang, R., Jiang, X., Qiao, J., Wang, Z., Tong, A., Yang, J., et al. (2021). Antimicrobial Peptide DP7 with Potential Activity against SARS Coronavirus Infections. Signal. Transduct Target. Ther. 6 (1), 140. doi:10.1038/s41392-021-00551-1

Zhao, H., To, K. K. W., Sze, K. H., Yung, T. T., Bian, M., Lam, H., et al. (2020). A Broad-Spectrum Virus- and Host-Targeting Peptide against Respiratory Viruses Including Influenza Virus and SARS-CoV-2. Nat. Commun. 11 (1), 4252. doi:10.1038/s41467-020-17986-9

Zhao, H., Zhou, J., Zhang, K., Chu, H., Liu, D., Poon, V. K., et al. (2016). A Novel Peptide with Potent and Broad-Spectrum Antiviral Activities against Multiple Respiratory Viruses. Sci. Rep. 6, 22008. doi:10.1038/srep22008

Zhao, Y., Zhang, M., Qiu, S., Wang, J., Peng, J., Zhao, P., et al. (2016). Antimicrobial Activity and Stability of the D-Amino Acid Substituted Derivatives of Antimicrobial Peptide Polybia-MPI. AMB Express 6 (1), 122. doi:10.1186/ s13568-016-0295-8

Conflict of Interest: The use of AMPs as anti-SARS-CoV-2 agents has been submitted as an invention disclosure to Case Western Reserve University. SG and $\mathrm{AW}$ are listed as co-inventors.

Copyright $\odot 2021$ Ghosh and Weinberg. This is an open-access article distributed under the terms of the Creative Commons Attribution License (CC BY). The use, distribution or reproduction in other forums is permitted, provided the original author(s) and the copyright owner(s) are credited and that the original publication in this journal is cited, in accordance with accepted academic practice. No use, distribution or reproduction is permitted which does not comply with these terms. 